\title{
Japan's key "X-factor" for low COVID-19 mortality may be its culture of wearing face masks
}

\author{
Daisuke Miyazawa $^{1}$ \\ ${ }^{1}$ Affiliation not available
}

July 2, 2020

Many have wondered if Japan possessed an "X-factor" that led to a low COVID-19 death rate.

We note that the mask non-wearing rate in mid-March alone was predicted to contribute up to $72 \%$ of variations in the number of deaths per million ${ }^{1}$. In addition, there was a remarkable difference in face mask wearing rates between Western countries and Asian countries, especially in East Asian countries including Japan $^{1}$. The county's policy for wearing a face mask alone cannot explain this significant difference. For example, there is a high rate of wearing face masks in Japan even though this practice has never been declared mandatory. We speculate that cultural differences may be the major reason.

Many Japanese wear surgical masks on a daily basis not with the purpose of shedding infections or pollens but to achieve inscrutability, similar to the Westerners wearing sunglasses.

It is referred to as "mask dependency" in a number of cases ${ }^{2}$. While people may wish to achieve anonymity, they also want to avoid making others uncomfortable. Jack, Caldara, and Schyns state, "whereas Western Caucasian internal representations predominantly featured the eyebrows and mouth, East Asian internal representations showed a preference for expressive information in the eye region" ${ }^{3}$. This tendency may be the major reason why it is considered rude to wear sunglasses among eastern Asians and why wearing face masks among Westerners is considered suspicious, which could be why the western population exhibits a low face mask wearing rate.

Additionally, the Japanese generally remain silent while using public transportation as loudness is a sign of rudeness in Japan ${ }^{4}$. This may also contribute to the "X-factor" because a very high proportion of aerosols are exhaled from asymptomatic individuals while speaking rather than breathing ${ }^{5}$. In addition, the viral density of aerosols is expected to vary between speaking and breathing as the origin of the aerosols is different. Aerosols originating from the mouth may contain more virus than those from the lungs in asymptomatic individuals.

Although face mask wearing has not yet been proven as an independent risk factor of COVID-19 mortality, a high rate of mask wearing in Japan may be the major candidate for the so called "X-factor."

\section{References}

1. Miyazawa D, Kaneko G. Face mask wearing rate predicts country's COVID-19 death rates. medRxiv 2020.06.22.20137745; doi: https://doi.org/10.1101/2020.06.22.20137745

2. Li T. "Mask Appeal: The Addiction of Surgical Masks in Japan." The Straits Times, Singapore Press Holdings Ltd. Co, 7 Apr. 2017,www.straitstimes.com/asia/east-asia/mask-appeal.

3. Jack RE, Caldara R, Schyns PG. Internal representations reveal cultural diversity in expectations of facial expressions of emotion. J Exp Psychol Gen. 2012;141(1):19-25. doi:10.1037/a0023463

4. Baseel C. 15 Rude Things Not to Do on Trains in Japan. 9 Sept. 2019, japantoday.com https://japantoday.com/category/features/lifestyle/15-rude-things-not-to-do-on-trains- 
in-japan

5. Buonanno G, Stabile L, Morawska L. Estimation of airborne viral emission: Quanta emission rate of SARS-CoV-2 for infection risk assessment. Environ Int. 2020;141:105794. doi:10.1016/j.envint.2020.105794

Daisuke Miyazawa, $\mathrm{MD}^{1}$ Gen Kaneko, $\mathrm{PhD}^{2}$

\section{Authors' affiliations}

${ }^{1}$ Miyazawa Clinic, Hyogo, Japan

${ }^{2}$ School of Arts \& Sciences, University of Houston-Victoria, 3007 N. Ben Wilson, Victoria, TX 77901 Tel: $361-570-4251$

kanekog@uhv.edu

ORCID ID: 0000-0003-4295-5123

\section{Corresponding author's details}

Daisuke Miyazawa

Miyazawa Clinic

1-6-5 Akuraminamin Takarazuka

Hyogo 665-0823

Japan

kusami1@ybb.ne.jp

$+8179784522$

ORCID ID:0000-0001-9743-1242

\section{Contributor and guarantor information}

Both DM and GK contributed to the conception and design of the work; the acquisition, analysis, and interpretation of data; and drafting and revision of the manuscript. DM and GK approved the current version of the manuscript and agree to be accountable for all aspects of the work.

Word count: 350

Disclosure: The authors declare no conflicts of interest. 